\title{
Pediatric cervical spine
}

\author{
DOUGLAS BROCKMEYER \\ Department of Neurosurgery, Primary Children's Medical Center, University of Utah, Salt lake City, \\ Utah
}

Like the children we care for, our knowledge base of the pediatric cervical spine is steadily growing. This issue of Neurosurgical Focus is intended to augment that knowledge base by concentrating exclusively on issues regarding the subaxial pediatric cervical spine. A number of authors have contributed their expertise so that a wide variety of important topics are covered. The topics range from managing traumatic injuries of the pediatric cervical spine to evaluating difficult deformity problems after spinal cord tumor resection. Original and review articles are included to give the reader both historical perspective and cuttingedge knowledge of pediatric cervical spine management principles. It is hoped that this issue of Neurosurgical Focus and its contents will be a springboard toward further understanding of this important and fascinating topic. 